\title{
O EXTERMÍNIO DE MENINOS DE RUA NO BRASIL
}

Umberto Guaspari Sudbrack

\begin{abstract}
Resumo: O artigo realiza uma análise interdisciplinar do fenômeno do extermínio de meninos de rua, no Brasil, entre 1985 e 1995, que é resultado da ação de grupos de extermínio, da omissão do Estado e da indiferença da sociedade civil em relação ao problema, gerando a falta de controle e a impunidade dos agentes dessas práticas criminosas.
\end{abstract}

Palavras-chave: grupos de extermínio; meninos de rua; política criminal.

Abstract: This article undertakes an interdisciplinary analysis of the extermination of street children in Brazil between 1985 and 1995, the result of the action of extermination groups, governmental neglect and societal indifference. Taken together, all of this leads to a lack of control and to the impunity of those who commit these criminal acts.

Key words: extermination groups; street children; criminal policy.

$\mathrm{O}$ extermínio de meninos de rua no Brasil ocorre principalmente nas grandes cidades, como Rio de Janeiro, São Paulo, Salvador e Recife. De acordo com o conceito adotado pelas Nações Unidas e elaborado por Lusk e Mason, a expressão designa toda criança (menino ou menina) para a qual a rua (no sentido mais amplo do termo, o que inclui casas não habitadas, terrenos baldios, por exemplo) tornou-se sua moradia e/ ou sua fonte de sobrevivência, e que não tem proteção, não é convenientemente vigiada ou orientada por um adulto responsável. Esta expressão refere-se a crianças desprovidas de recursos e que moram ou passam a maior parte de seu tempo na rua, sem serem necessariamente infratoras. $\mathrm{O}$ fenômeno dos meninos de rua fornece uma imagem dramática dos países do Terceiro Mundo, sobretudo na América Latina. ${ }^{1}$ Entretanto, os países desenvolvidos também podem ter esse problema. Crianças provenientes das camadas mais pobres dos países ricos adotam cada vez mais a rua na busca de sua sobrevivência. São, sobretudo, filhos de imigrantes cujos pais deixaram seu país de origem em busca de melhores condições de vida para a família (Pilotti; Rizzini, 1993:51).
Essas crianças moram normalmente nos bairros pobres das periferias urbanas e nas favelas que se multiplicam. A maioria volta para casa todos os dias ou esporadicamente. Todavia, são menos numerosos aqueles que moram nas ruas.

O tema limita-se aos homicídios praticados contra os meninos de rua, no Brasil, no período 1985-1995. Tais crimes não são conseqüência imediata da violência doméstica e correspondem ao chamado "extermínio de crianças", o que a Comissão Nacional de Combate à Violência, formada por organizações não-governamentais e por representantes do governo federal para controlar a violência contra crianças, define como a "presunção de homicídios voluntários contra aqueles que têm menos de 18 anos, por motivos extrafamiliares, com o fim objetivo ou subjetivo de impor uma ordem extralegal, seja ou não o autor conhecido" (Human Rights Watch/Americas, 1994:11).

A Comissão de Controle e de Prevenção do Extermínio do Conselho dos Direitos da Criança e do Adolescente do Rio Grande do Sul, composta por representantes do Ministério Público, da Polícia Civil, da Polícia Militar, 
do Movimento Nacional dos Meninos de Rua, da Ordem dos Advogados do Brasil e da Pastoral do Menor define o extermínio, referindo-se a crianças e adolescentes, como "a ação individual ou de grupo, concebida e organizada com o fim da eliminação, por qualquer meio, de criança ou adolescente considerada ou suspeita de se encontrar em situação de risco pessoal e social ou para ocultar práticas delitivas" (Brasil, 1994:8-9, citado por Sudbrack, 1996:114).

Para que haja extermínio, é necessário que o resultado da ação seja a morte. Além disso, é preciso que a vítima do homicídio seja uma criança ou um adolescente. Se a conseqüência não for a morte, estamos diante de uma tentativa de homicídio. Por outro lado, a vítima pode enquadrar-se em uma situação de risco pessoal ou apresentar um comportamento não aceito socialmente. Nessa situação, estariam desde aqueles que cometeram atos infracionais, até aqueles com presença considerada incômoda em lugares públicos. A Comissão entende que, para se poder falar de extermínio, é necessário mais do que o simples dolo, elemento característico do homicídio doloso, mas a presença da vontade deliberada de eliminar determinada pessoa menor de idade em virtude de aspectos comportamentais anteriores, não aceitos pelo autor ou pelos autores. A Comissão tratou essa característica como sendo o "dolo de extermínio" (Brasil, 1994:8, citado por Sudbrack, 1996:114).

Não existe, porém, definição legal de extermínio. Embora a Lei $\mathrm{n}^{\circ} 8.930$, de 6 de setembro de 1994, que dá uma nova redação ao artigo 19 da Lei no 8.072, de 25 de julho de 1990, tenha criado o crime de homicídio qualificado por ter sido praticado em atividade típica daquela de um grupo de extermínio, não definiu juridicamente o que seja o extermínio.

Apenas uma pequena parte dos chamados meninos de rua acaba cometendo infrações. Mesmo assim, são considerados uma população de risco para os grupos dominantes da sociedade brasileira.

O fenômeno do extermínio de meninos de rua é o resultado de uma articulação entre os grupos de extermínio, da omissão e ausência de defesa das crianças pelo Estado, assim como da indiferença da sociedade civil em relação ao problema.

A prática repressiva brasileira opõe-se à legislação penal liberal e aos princípios constitucionais, impedindo a efetividade dos direitos humanos e ameaçando o regime democrático. Uma das manifestações mais dramáticas dessa realidade é, hoje, o extermínio dos meninos de rua.

\section{ASPECTOS HISTÓRICOS DA REPRESSÃO NO BRASIL}

A violência em relação a certas camadas da população nacional tem origem em práticas antigas, como, por exemplo, aquelas existentes durante o regime colonial e o período escravocrata. Com efeito, os índios e os escravos negros foram vítimas da violência dos agentes do Estado, durante mais de cinco séculos, sendo muitas vezes eliminados fisicamente. Na República, implantada em 1889, a repressão policial contra os desfavorecidos destaca-se, sobretudo, nos períodos de autoritarismo político, como o Estado Novo (1937-1945) e o regime militar (19641985). Se a partir dos anos 20 e 30, inicialmente os anarquistas, depois, os comunistas, se durante o regime militar, todos que se opunham a este, eram considerados como "inimigos da sociedade" e, portanto, objeto de uma forte repressão, nos anos 80, os meninos de rua passam a constituir esse grupo "perigoso", o que enseja um controle social severo dos mesmos com apelo, inclusive, à eliminação física.

Uma estrutura socioeconômica extremamente desigual, trazendo enormes tensões sociais, desenvolve-se, no Brasil, desde a escravidão até nossos dias, quando o fosso social que separa os ricos, as classes médias e os pobres é enorme.

A desigualdade social que divide a sociedade brasileira é a principal razão da criminalidade, inclusive a dos menores e, conseqüentemente, de sua repressão. Segundo uma estimativa do Instituto Brasileiro de Geografia e Estatística - IBGE, o Brasil tem a pior distribuição de renda dentre os países de mais de 10 milhões de habitantes, sendo que os $20 \%$ mais ricos têm uma renda 26 vezes maior do que os 20\% mais pobres (PNUD, 1991:25). Dados mais recentes que constam do Atlas do Desenvolvimento $\mathrm{Hu}$ mano, divulgado pelo PNUD - Programa das Nações Unidas para o Desenvolvimento, Ipea - Instituto de Pesquisa Econômica Aplicada e Fundação João Pinheiro, revelam que de 1991 a 2000, a distribuição de renda piorou em dois terços dos municípios brasileiros. Na média geral do Brasil, a desigualdade de renda também aumentou na última década, e o país já ocupa o sexto lugar entre os países com pior distribuição de renda (Manfrini, 2003). Além das desigualdades presentes nos estados da Federação brasileira, constata-se a existência de disparidades regionais extremamente marcantes entre os estados do Norte e os do Sul. Excetuando razões conjunturais, como a transferência de recursos que permitem assegurar o pa- 
gamento da dívida externa do país, essa situação é mantida e reproduzida historicamente pela grande hierarquização social. Amplas camadas da sociedade vivem em condições miseráveis de marginalidade, que podem ser comparadas àquelas que conhecem os países menos desenvolvidos da Ásia e da África.

A questão da distribuição da renda é fundamental para o estudo da violência brasileira. Com efeito, a miséria é hoje a chave que explica o fenômeno da eliminação física dos marginais e daqueles considerados como "inimigos da sociedade", inclusive os meninos de rua.

Apesar da emergência de novos governos democráticos, persiste a violência do Estado e de certos setores da sociedade civil contra os grupos desfavorecidos. Com efeito, as camadas populares são submetidas com muito mais freqüência a um estatuto de extralegalidade do que se beneficiam de um quadro realmente legal (Pinheiro, 1994:19).

Além da escravidão, outros dados fornecidos pela história econômica e política do Brasil, como o latifúndio, o patrimonialismo e a ausência de democracia mostram que a sociedade brasileira baseia-se em relações sociais fortemente hierarquizadas, o que dá origem a uma cultura política marcada pelo descrédito do direito. Isto significa que, sob a estrutura jurídica do Estado de Direito, desenvolve-se toda uma cultura da ironia, e mesmo do cinismo, ninguém desconhecendo que a lei só vale para alguns. Assim, não surpreende que a sociedade ajuste suas contas com os criminosos vindos das classes populares sem qualquer preocupação quanto aos direitos fundamentais dos mesmos. A tortura, os castigos físicos, a execução pura e simples de ladrões, a detenção de meros "suspeitos", a qualquer hora da noite, mantidos presos, depois, todos esses atos que violam a lei representam uma prática constante e habitual da polícia no Brasil (Oliveira, 1992:449450).

Durante o regime militar, não se falava de direitos civis ou de direitos humanos senão para garantir a proteção dos opositores políticos. Sempre que, nessa época ou posteriormente, se buscou ampliar esses direitos ao conjunto da sociedade, particularmente aos pobres, a resistência foi grande. A reação contra a ampliação dos direitos usou como pretexto o temor da insegurança para estigmatizar os trabalhadores e os marginais. Paradoxalmente, a mobilização social dos marginais contra a segregação sofrida na sociedade levou ao desenvolvimento de novos modelos de segregação social e espacial - dos quais a "limpeza" dos marginais e uma desconfiança renovada a seu respeito são componentes importantes (Pinheiro, 1994:42).

Após o regime militar, no entanto, as violações de direitos humanos não cessaram. Ao contrário, voltaram aos locais onde sempre estiveram: delegacias de polícia e prisões onde já se torturava antes do regime militar e onde se continua a torturar. A tortura, com efeito, praticamente desaparecida na Europa, entre o final do século XVIII e o aparecimento, no século XX, dos regimes totalitários, acompanha sem descompasso a história do Brasil (Oliveira, 1997:2-3).

Mostrou Roberto Kant de Lima que a ideologia liberal, universalista e igualitária é insuficiente para interpretar as práticas judiciais e para compreender os ideais formais da justiça no Brasil. Quando estes, eventualmente, são alcançados pelo Poder Judiciário ou pela polícia, aceita-se que eles estão atingindo apenas um segmento limitado da população. No sistema criminal brasileiro, a função mais importante exercida pela polícia consiste em rotular, categorizar as pessoas. As práticas policiais e o sistema judicial de categorização estão ligados à crença de que os valores liberais devem ser "adaptados" em sua aplicação na sociedade brasileira (Lima, 1995:143/144).

Os grupos desfavorecidos sempre sofreram um tratamento ilegal no sistema criminal brasileiro, tanto nos períodos de regime autoritário quanto naqueles de regime constitucional. Nenhum dos períodos de transição para a democracia, seja o que seguiu a ditadura do Estado Novo (1937-1945), ou o que veio após o regime militar de 1964 a 1985, mudou essa realidade. O autoritarismo revela, na prática, o que é dissimulado nas fases democráticas: o caráter da repressão autoritária e os limites da violência física ilegal. O extermínio de pessoas, prática largamente difundida durante os períodos de ditadura, prolongou-se nos períodos de transição política, quando a manutenção da ordem se militariza² (Pinheiro, 1994:49). Entre 1981 e 1989, por exemplo, 3.900 suspeitos e criminosos foram mortos pela Polícia Militar, em São Paulo. Vagabundos, criminosos, prostitutas e menores nocivos tornam-se "inimigos internos" (Pinheiro, 1994:49).

A tortura, a eliminação de suspeitos e outras práticas rotineiras aplicadas sistematicamente aos grupos populares (invasões de domicílio, seqüestros, assassinatos, massacres) são toleradas. O discurso oficial emprega, na maior parte dos casos, a retórica da recusa, que não se traduz por nenhuma ação concreta, o que consagra a impunidade dos agentes da violência ilegal. O combate contra a criminalidade de direito comum durante os dois governos de 
transição política não difere muito daquele travado durante as ditaduras e é acompanhado pela militarização da polícia. Os governos democráticos da transição após 1985 não foram capazes de controlar a violência ilegal dos aparelhos repressivos que se beneficiam de uma ampla autonomia, o que torna difícil seu controle. A democratização do governo não significa automaticamente a democratização do aparelho repressivo. A existência das práticas democráticas nos aparelhos de repressão dependerá da mobilização da sociedade civil que legitima, hoje, as práticas autoritárias (Pinheiro, 1994:51-52).

\section{UMA ABORDAGEM DE POLÍTICA CRIMINAL}

Empreendemos um estudo interdisciplinar que se relaciona diretamente com a questão do autoritarismo e da efetividade dos direitos humanos no Brasil. Trata-se da abordagem de política criminal que situa a questão da criminalidade e do controle social em uma perspectiva integrada pelo direito penal, pela política criminal e pelos direitos humanos.

De acordo com Mireille Delmas-Marty, a política criminal compreende o conjunto dos procedimentos através dos quais o corpo social organiza as respostas ao fenômeno criminal. Todavia, as práticas penais não se encontram sós no campo da política criminal. Acham-se englobadas por outras práticas de controle social: práticas não penais (por exemplo, sanções administrativas), práticas não repressivas como a prevenção, a reparação ou a mediação e, às vezes, até mesmo práticas não-estatais (práticas repressivas de milícias privadas, ações de protesto do tipo Amnesty International ou medidas disciplinares, evocando o termo certos tipos de regulação profissional (DelmasMarty, 1992:13).

A relação entre direito penal e direitos humanos é uma relação ambígua que expressa uma tensão entre dois pólos, às vezes antinômicos e às vezes mesclados. A antinomia com os direitos humanos está, de fato, no cerne da justiça penal, fundada no direito de punir, isto é, de atingir certos direitos fundamentais da pessoa, a começar por aquele de ir e vir livremente. E, no entanto, o sistema penal preenche igualmente uma função de proteção dos direitos fundamentais, sobretudo pelo viés da incriminação penal (Delmas-Marty, 1992:28).

Zaffaroni sustenta que existe uma certa contradição entre os direitos humanos e o direito penal, pois aqueles assinalam um programa de realização da igualdade dos direitos, ao passo que os sistemas penais são instrumen- tos que confirmam a desigualdade dos direitos em todas as sociedades. Até mesmo as próprias características dos sistemas penais violam os direitos humanos. É preciso, então, buscar uma verdadeira legitimação para o sistema penal (Zaffaroni, 1991:149). A dor e a morte que produzem nossos sistemas penais latino-americanos denunciam um discurso jurídico-penal totalmente distanciado da realidade. Ele produz a morte em massa, trabalha com um alto nível de violência, negligencia a tutela da vida, tem uma formação autoritária. É, enfim, perverso e falso. Cabe aos operadores e aos pesquisadores da justiça criminal a tarefa de mudar o sistema penal (Zaffaroni, 1991:12-13).

É necessário aproximar o direito penal das outras ciências, tais como a criminologia, a política criminal e a sociologia, a fim de romper o pressuposto positivista que considera o direito penal isolado e auto-suficiente. A dogmática penal deve adaptar-se às novas possibilidades trazidas pela visão interdisciplinar no que diz respeito ao estudo da criminalidade, sobretudo para evitar a separação entre a teoria e a prática. Quando se fala das relações entre a política criminal e os direitos humanos, pensa-se no estudo interdisciplinar, no direito comparado, assim como nos sistemas e mecanismos internacionais e regionais de proteção aos direitos humanos. Imagina-se a possibilidade de tornar o sistema criminal mais democrático, de modo que os direitos e as garantias individuais se tornem verdadeiramente concretos (Sudbrack, 2001:87).

A sociologia pode colaborar com o direito penal denunciando as violações à integridade física e moral das classes desprotegidas, dos "marginalizados" que desconhecem a efetividade de seus direitos, não assegurados, na prática, pela norma positivada. A sociologia pode ajudar, enquanto ciência social aplicada, ao propor um regime de enunciados contra a violência e ao organizar um público socializado, no interior do Estado e da sociedade civil, capaz de se indignar contra a exclusão social, mantendo uma consciência da injustiça (Tavares dos Santos, 1995:281-298).

O fenômeno criminal, em sentido amplo, não se constitui tão somente pelas infrações penais, contravenções, delitos e crimes, mas pelo conjunto dos comportamentos incriminados ou não pela lei penal e considerados como perturbadores da ordem social, porque se expressam mediante uma recusa às normas. Para combater esses comportamentos delinqüentes ou desviantes, a política criminal tenta propor respostas estatais ou sociais no respeito aos direitos humanos. Assim definida, a política criminal não se reduz, pois, ao direito penal nem ao procedimento 
penal ou à criminologia, mas inscreve-se em um projeto global e em uma estratégia global: a política social de um determinado Estado (Lazerges, 1987:5).

Adotam-se os modelos de política criminal de Mireille Delmas-Marty para compreender a política criminal brasileira, particularmente o fenômeno do extermínio de meninos de rua no país.

Sendo a infração e o desvio dois tipos de comportamento contra as normas, e as respostas estatal e social dois tipos de reação do corpo social, é a partir desses quatro elementos que se define o jogo das relações fundamentais, alternativas e complementares, de acordo com as quais se organiza todo sistema de política criminal, isto é, o instrumento que tornará possível uma análise transversal dos diferentes sistemas, apesar de sua extrema diversidade; a ferramenta empregada é independente das realidades que dizem respeito a cada país, a fim de possibilitar um duplo trabalho comparativo: comparação dos sistemas em vigor em diferentes países de acordo com modelos construídos, a partir do jogo das relações e comparação dinâmica das mudanças desses sistemas segundo as imposições (nacionais e/ou internacionais) que os limitam, ou seja, pelos principais movimentos de política criminal (Delmas-Marty, 1992:68).

Os modelos de política criminal mencionados dizem respeito às quatro relações fundamentais e ao esquema já mencionado. A elaboração de modelo implica a busca do princípio segundo o qual se organizam as relações fundamentais (as relações derivadas intervêm somente no momento da construção de variantes). Há uma hierarquia entre as relações, sendo algumas privilegiadas ou dominantes (a autora marca-as com o sinal +), outras mais frágeis, reduzidas ou ausentes (sinal -). Observa-se um fenômeno de dominância entre formas estatais e sociais. Ao sistema oficial de política criminal - aquele definido pelo direito em vigor - sobrepõem-se, entretanto, múltiplos sistemas surgidos da prática (Delmas-Marty, 1992:75-76).

Os modelos são construídos, então, a partir da distinção entre a infração e o desvio e da maior ou menor participação do Estado no controle dos comportamentos de recusa às normas. Uma primeira grande distinção aparece entre modelo estatal (o Estado assume esse controle) e modelo social (a sociedade civil se encarrega dele). Dentre os modelos estatais, temos o modelo Estado-Sociedade liberal, o modelo Estado autoritário e o modelo Estado totalitário. Dentre os modelos sociais, encontram-se o modelo Sociedade autogestionária e o modelo Sociedade libertária (Delmas-Marty, 1992:85).
O modelo Estado-Sociedade liberal, inspirado na ideologia liberal, tem como valor de referência a liberdade garantida pela distinção entre infração e desvio e pela limitação do campo de intervenção do Estado apenas ao domínio da infração. A tradição liberal repousa em uma relação privilegiada com a lei, ilustrada nos direitos penais da família romano-germânica por um grande respeito ao princípio de legalidade. A polícia é auxiliar do sistema penal; sua autonomia só existe nos modelos autoritários ou totalitários (Delmas-Marty, 1992:88 e ss.).

No modelo Estado autoritário, existe uma distinção entre desvio e infração, mas a resposta dada tanto a um quanto à outra provém do Estado, seja diretamente, por meio do direito (penal, administrativo, civil), seja mediante as intervenções coercitivas da polícia ou da administração médico-social. A sociedade civil é excluída de qualquer resposta. A resposta estatal ao desvio é característica desse modelo. O reforço do poder policial e das instâncias médico-sociais dá lugar às intervenções coercitivas do Estado (Zambrano, 1988:8).

No modelo Estado totalitário, a distinção entre desvio e infração sequer existe. O Estado responde, de modo permanente e indiferenciado, a todos os comportamentos que considera como recusa às normas. Uma das técnicas jurídicas utilizadas é o raciocínio por analogia. O juiz pode fundar sua decisão em qualquer texto legal, ou até mesmo basear-se nos princípios em que se inspirou o direito do país (por exemplo, a Alemanha hitlerista). O apelo a incriminações demasiadamente amplas do tipo "segurança nacional" pode levar, então, ao mesmo resultado. Uma outra característica do modelo totalitário de política criminal é a submissão da autoridade ao Poder Executivo, submissão que passa geralmente por dois meios: a nomeação dos magistrados de confiança e a redução da competência das jurisdições de direito comum em proveito das jurisdições de exceção (Zambrano, 1988:8-9).

Este modelo pode ser aplicado mais particularmente ao estudo das práticas de extermínio de meninos de rua no Brasil, percebendo a passagem do modelo Estado-Sociedade liberal ao modelo Estado totalitário. Constata-se, por exemplo, a primazia do Poder Executivo, a assimilação dos menores desviantes a delinqüentes, sobretudo por meio das ações da polícia, a prática da pena de morte, mediante as execuções sumárias de meninos de rua, assim como o reforço das relações com as instâncias sociais com vistas a uma participação repressiva. A repressão é efetuada por grupos de extermínio que elaboram ações de eliminação ditas de limpeza. Esses esquadrões da morte 
são compostos ou por policiais e ex-policiais, ou por membros de milícias privadas que vendem sua proteção a comerciantes e a outras pessoas.

Os modelos sociais dividem-se, por sua vez, em modelo Sociedade autogestionária e modelo Sociedade libertária. O primeiro caracteriza-se, particularmente, pela existência de uma resposta social à infração (I-Rs), pois a resposta social ao desvio já aparece com o modelo Estado-sociedade liberal. Esse modelo pode manifestar-se, a partir da relação I-Rs, por diversas variantes alternativas. Com efeito, as redes de auto-regulação que ela determina organizam-se diferentemente quando dizem respeito a uma fração estruturada do corpo social que estabelece normas específicas ligadas a seu tipo de atividade e pretende ela própria geri-las de modo mais ou menos independente do Estado - redes autodisciplinares -, ou quando a vítima, individual ou coletiva (bancos, grandes lojas, empresas), mas isolada do resto do grupo social, usa o pretexto de uma falha do Estado para garantir a segurança das pessoas e dos bens e organiza suas próprias redes de autodefesa. Neste último caso, é fundamental o papel das milícias privadas. Da defesa contra as infrações, elas passam à defesa agressiva e, depois, à agressão. Aumenta, então, o risco de concorrer muito abertamente com o Estado, exercendo em seu lugar uma parte do direito de punir, atributo da soberania tradicionalmente reservada a seu monopólio (Delmas-Marty, 1992:224-242). Com efeito, os comerciantes empregam vigias ou contratam agentes dos esquadrões da morte para enfrentar os pequenos furtos cometidos por menores.

O último modelo, aquele da Sociedade libertária, caracteriza-se pelo apagamento do Estado. Sem referência ao mesmo, o conjunto das relações sociais, particularmente as relações conflituais, é deixado à sua diversidade primeira sem que nenhuma verdadeira definição dos comportamentos de recusa das normas venha circunscrever o espaço das respostas do grupo social. Não há, portanto, distinção entre infração e desvio (Delmas-Marty, 1992:242-262). Esse modelo comporta, dentre outras, as práticas dos justiceiros, que se reduzem à vingança privada e que levarão ao modelo totalitário, pois há, evidentemente, junção entre os dois modelos.

Interessante observar grande semelhança de nosso sistema de política criminal com aquele do México. Com efeito, Zambrano reconhece manifestações do modelo autoritário ou mesmo totalitário no seio da política criminal mexicana, que visam claramente certas categorias de pessoas, ou seja, os prisioneiros, os menores, os doentes mentais e os estrangeiros, afetando, devido ao grande número de indivíduos atingidos, toda a política criminal. Porém, outras manifestações totalitárias perturbam mais diretamente ainda o conjunto do sistema penal mexicano: a existência de um poder policial cada dia maior e que questiona diretamente os direitos humanos mais fundamentais, isto é, a liberdade e a vida. Esse poder policial é uma das características dos Estados totalitários, que respondem a qualquer recusa das normas por uma repressão que não distingue a infração do desvio. O México se acha confrontado com o paradoxo de uma constituição liberal e práticas que atentam freqüentemente contra os direitos humanos (Zambrano, 1991:217-218).

Quanto à existência de uma legislação liberal, mas com práticas autoritárias e/ou totalitárias, o mesmo acontece no Brasil. Wanda Capeller mostra que, não obstante nosso país possua uma carta constitucional moderna, no âmbito dos direitos sociais e das liberdades públicas (a Constituição de 1988), as práticas ilegais das elites jamais deixaram de prevalecer, mesmo após 1988, o que prova a manutenção da concepção autoritária do Estado pelas elites (De Lemos Capeller, 1991:7-8). Existe, com efeito, uma verdadeira cultura política do autoritarismo no Brasil. As políticas escolhidas, cujos animadores foram muitas vezes os juristas, revelam uma visão elitista do campo social e uma concepção do controle penal que se identifica com a repressão pura e simples das classes desfavorecidas. Ainda hoje, a preocupação com a eficácia repressiva está presente na vida nacional e encontra-se no centro de todos os assuntos ligados à delinqüência e à segurança pública (De Lemos Capeller, 1991:10-11).

Com efeito, no Brasil, existe uma espécie de cultura política defendendo a eliminação física dos "inimigos internos". Comprova-se tal afirmativa pela existência dos esquadrões da morte dos anos 70 e dos novos grupos de extermínio, surgidos nos anos 80. A ação desses grupos enquadra-se nos modelos de política criminal de Mireille Delmas-Marty, sobretudo nos modelos estatais autoritário e totalitário e no modelo societário Sociedade Libertária, que mostram o risco, no mundo atual, de retorno à vingança privada típica das sociedades primitivas. No Brasil, essa possibilidade agrava-se pela existência do autoritarismo do Estado e da sociedade civil, bem como da situação econômica desfavorável que leva enormes contingentes da população à miséria. Os membros desses grupos excluídos tornam-se o alvo preferido da polícia e das redes sociais que aplicam a vingança privada como tática de eliminação dessas pessoas. 
Por outro lado, o sistema criminal brasileiro, formado pela Polícia, Ministério Público, Poder Judiciário e Sistema Penitenciário, mostra-se ilegítimo, particularmente em face da carência de novos paradigmas, de âmbito interdisciplinar, capazes de torná-lo democrático e coerente com os princípios consagrados no Estado Moderno de Direito.

Analisando-se a evolução das Constituições e do Direito Penal brasileiro, percebe-se a distância entre teoria e prática, ou seja, o direcionamento do modelo liberal aos modelos autoritário e totalitário de política criminal. É que, não obstante a existência de leis penais liberais e de princípios constitucionais democráticos, há uma prática autoritária e totalitária do Estado e mesmo de setores da sociedade civil que torna a igualdade de todos perante a lei uma grande ficção. Historicamente, os agentes do Estado responsáveis por violações de direitos humanos sempre se beneficiaram da impunidade. Existe um descompasso entre a letra da Constituição e das leis em geral e o funcionamento das instituições encarregadas de efetivar os direitos da população. Leis criminais mais recentes no combate à violação dos direitos humanos deveriam ser efetivamente aplicadas pelos juízes quando chamados a decidir, por força dos inquéritos policiais e das denúncias apresentadas pelo Ministério Público. Citam-se como exemplos a Lei $\mathrm{n}^{0} 9.455 / 97$, que define os crimes de tortura e dá outras providências, e a Lei $n^{\circ} 8.930$, de 6 setembro de 1994, que deu nova redação ao artigo $1^{\circ}$ da Lei $\mathrm{n}^{\circ} 8.072$, de 25 de julho de 1990 (Lei dos Crimes Hediondos), em conformidade com o art. $5^{\circ}$ da Constituição Federal, criando o chamado "homicídio, quando praticado em atividade típica de grupo de extermínio". A criação desse tipo penal representa o reconhecimento, pelos poderes Executivo e Legislativo, da existência do extermínio, no país, e o desejo de combatê-lo.

Deve-se assinalar, enfim, a insuficiência do direito interno para resolver o problema das violações de direitos fundamentais no país, e, portanto, a necessidade de serem aplicados princípios supranacionais, bem como a jurisdição internacional e/ou regional, para combater tais violações, sobretudo o direito à vida. A integração do direito internacional com o direito interno brasileiro faz-se necessária, não sendo procedentes os argumentos no sentido de que a aceitação dessas jurisdições supranacionais, em nível dos direitos humanos, fira a soberania nacional. Tal posicionamento corresponde a uma perspectiva conservadora e autoritária do direito, própria de uma visão jurídica positivista.

\section{CONSIDERAÇÕES CONCLUSIVAS}

Entre 1985 e 1995, ocorreu, no Brasil, o extermínio de meninos de rua, no meio urbano, especialmente em grandes cidades, como Rio de Janeiro, São Paulo, Salvador e Recife.

Apesar da implementação da democracia há, em nosso país, uma tradição de práticas autoritárias e totalitárias particularmente dos agentes públicos - que atentam contra os direitos humanos e permanecem, a partir de 1985, período que dá início à (re)democratização. Com efeito, existem certos grupos de pessoas que se tornam, ao longo dos anos, o alvo da violência ilegal do Estado e da sociedade. Inicialmente, foram os índios, depois os negros. Nos anos 20, os anarquistas; ao longo dos anos 30, os comunistas. Durante o regime militar, todos os que se opunham à ditadura. Nos anos 80, os meninos de rua tornam-se os "inimigos da sociedade".

Os grupos de extermínio desses menores têm origem nos esquadrões da morte dos anos 70. Muitos policiais do período do regime militar acabaram se engajando, posteriormente, nesses grupos. Os exterminadores são pagos por comerciantes e outros setores da sociedade, aos quais a ação ou mesmo a simples presença de meninos de rua perto de seus estabelecimentos causa transtorno e prejuízo.

Os grupos de extermínio são compostos, principalmente, por policiais militares que aproveitam o tempo livre, fora do trabalho, cometendo tais crimes para melhorar seus salários que são muito baixos. Também há, nos mesmos, policiais civis, ex-policiais e agentes de segurança privada.

O fenômeno do assassinato de meninos de rua resulta de uma articulação entre os grupos de extermínio, da omissão e da falta de defesa de crianças e adolescentes, pelo Estado, assim como da indiferença da maioria da sociedade civil em relação ao problema.

A impunidade dos agentes de extermínio de meninos de rua deve-se, em grande parte, à ineficácia da Polícia Civil, na elaboração do inquérito policial, o que imobiliza a atuação do Ministério Público. Os inquéritos elaborados pela Polícia Militar, em razão de diversas irregularidades, conduzem também à impunidade dos policiais militares suspeitos desses homicídios. O Poder Judiciário, que já é lento no julgamento dos processos em geral, fica limitado, ainda mais, pelo mal funcionamento da Polícia.

A independência do Ministério Público e do Poder Judiciário deve ser garantida para que seus membros pos- 
sam supervisionar as atividades policiais. Nessa perspectiva, o Executivo não deve se sobrepor aos mesmos.

Temos, no país, uma Constituição democrática e um Código Penal liberal, indicando a teoria a existência de um Estado de Direito. No entanto, na prática, um tratamento desigual prevalece em relação a certos grupos sociais, no âmbito do sistema criminal, existindo, paralelamente, uma desigualdade social e econômica quanto a esses grupos. A visão brasileira da democracia é muito particular: trata-se de declarar direitos a todos limitando o acesso dos mesmos a grupos restritos da sociedade.

As práticas de extermínio de meninos de rua inseremse nos modelos de política criminal de Mireille DelmasMarty, particularmente naquele do Estado totalitário. Daí a utilidade desses modelos. O fenômeno está ligado, efetivamente, ao predomínio do Executivo, à assimilação do menor ao delinqüente e à ação incontrolável e impune da polícia, características típicas do modelo totalitário de política criminal.

Também os modelos societários, principalmente aquele da Sociedade libertária, contribuem para a compreensão do problema. Há um risco evidente de retorno à vingança privada das sociedades primitivas, no Brasil. O extermínio de meninos de rua, por determinados grupos sociais, representa um certo tipo de resposta auto-regulamentadora do tipo autodefesa, que exprime uma escolha de política criminal, empreendida por esses setores, diante do que eles consideram como a ineficácia do sistema penal e, logo, do Estado. A ação dos justiceiros, os linchamentos e os grupos de extermínio beneficiam-se de um grande apoio, sobretudo dos segmentos mais carentes da população. Isto se insere, a toda evidência, no modelo societário Sociedade libertária, particularmente no submodelo vingativo.

A desigualdade social que divide a sociedade brasileira é o principal fator determinante da criminalidade e do comportamento desviante dos adolescentes e, conseqüentemente, da repressão que sofrem, inclusive com a eliminação física. Para combater tal realidade, é preciso mudar as condições socioeconômicas da população, atacando-se problemas básicos, como a concentração de renda, formulando políticas públicas que visem à promoção de reformas sociais, tendo por finalidade o desaparecimento das hierarquias e dos privilégios, bem como fornecendo uma resposta às reivindicações coletivas dos setores economicamente marginalizados.

É preciso dar efetividade aos direitos humanos, e para isso impõe-se combater o formalismo jurídico que apenas ressalta os direitos fundamentais sem dar-lhes força normativa, o que exige a implementação de mecanismos internacionais e regionais de defesa dos direitos humanos.
O isolamento do direito penal baseado em uma dogmática jurídica superada deve ser repelido por uma idéia de interdisciplinaridade e pelo desenvolvimento de aspectos realistas e críticos. Nesse sentido, a definição de política criminal adotada e o enfoque que lhe é inerente, representam a perspectiva mais adequada para combater o positivismo jurídico, principalmente quando ele se mostra insuficiente para lidar com certos fenômenos criminais que violam os direitos, como é o caso do extermínio de meninos de rua.

Tanto a União quanto os estados brasileiros omitiramse, no período 1985-1995, no controle do extermínio de meninos de rua. Tais omissões não se limitaram a não evitar tantas mortes, a não punir aqueles que violaram a lei, mas também a não fornecer a crianças e adolescentes, excluídos socialmente, as condições mínimas de dignidade humana previstas na legislação internacional, particularmente na Convenção dos Direitos da Criança da ONU.

Apenas a vontade política reforçada pelos princípios e processos de controle supranacional pode combater violações de direitos humanos, como o extermínio de meninos de rua.

\section{NOTAS}

$\mathrm{O}$ artigo tem por base os aspectos teóricos da tese de doutorado do autor intitulada "L'extermination des enfants de la rue au Brésil: étude de politique criminelle", sob a orientação da professora Mireille DelmasMarty, defendida em 18 de maio de 1999, na Universidade de Paris 1 (Panthéon-Sorbonne), para obtenção do título de Doutor em Direito.

1. A Colômbia, por exemplo, possui uma das mais altas taxas de homicídios do mundo. Em 1991, 2.800 crianças foram assassinadas. Para garantir a sobrevivência, os meninos de rua recorrem freqüentemente à prática de pequenos furtos ou outras infrações e, por isso, são considerados indesejáveis sociais. É comum que comerciantes e empresários locais, convencidos de que as crianças afugentam seus clientes, apóiem os "esquadrões da morte", que praticam a "limpeza social". Esses esquadrões são compostos por agentes da polícia nacional. Também na Guatemala existem ameaças, torturas e homicídios contra as crianças cujas condições sociais as levaram à rua. Denuncia-se até mesmo a participação das autoridades nessas mortes. Em tais países, as forças da ordem ameaçam igualmente aqueles que trabalham com essas crianças, geralmente voluntários que pertencem a organizações não-governamentais (Cf. Amnistía Internacional, 1994:5).

2. A atribuição da manutenção da ordem à Polícia Militar é prevista pela Constituição de 1988 (art. 144, § 5º).

\section{REFERÊNCIAS BIBLIOGRÁFICAS}

AMNISTÍA INTERNACIONAL. Niños bajo el terror, Revista Bimestral para los Países de Habla Hispanica, Londres, n.5, 8 p. enero 1994.

BRASIL. CONSELHO ESTADUAL DOS DIREITOS DA CRIANÇA E DO ADOLESCENTE DO RIO GRANDE DO SUL. Comissão 
Especial de Controle e Prevenção do Extermínio, Relatório final dos trabalhos. Porto Alegre: 1994. 57 p. Mimeografado.

DE LEMOS CAPELLER, W. La mise em oeuvre des politiques criminelles au Brésil: réception et adaptation des modèles occidentaux 1991, 527 p. Tese (Doutorado) - Faculté de Droit d'Amiens de l'Université de Picardie, Amiens, 1991.

DELMAS-MARTY, M. Les grands systèmes de politique criminelle. Paris: PUF, 1992. 242 p.

HUMAN RIGHTS WATCH/AMERICAS. Final Justice. Police and Death Squad Homicides of Adolescents in Brazil. New York, 1994. $41 \mathrm{p}$.

LAZERGES, C. La politique criminelle. Paris: PUF, 1987. 121 p.

LIMA, R. K. de. A polícia da cidade do Rio de Janeiro: seus dilemas e paradoxos. 2. ed. ver. Rio de Janeiro: Forense, 1995. 164 p.

MANFRINI, S. Distribuição de renda piora em dois terços dos municípios brasileiros. Folha Online - Brasil, São Paulo, 02/10/2003. Disponível em:

<http://www1.uol.com.br/folha/brasil/ult96u53999.shtml>.

OLIVEIRA, L. Culture démocratique et répression pénale. Quelques notes sur le Brésil et la France. Versão escrita de uma exposição no Centre de Recherches sur le Brésil Contemporain (EHESS). Paris, 1997. 19 p. Mimeografado.

Violation des droits de l'homme et la redémocratistion au Brésil: sous l'état scélérat, la société perfide ..., In: Droit et Société - Revue Internationale de Théorie du Droit et de Sociologie Juridique, n.22, Paris, LGDJ, p.447-464, 1992.

PILOTTI, F.; RIZZINI, I. A (des) integração na América Latina e seus reflexos sobre a infância. In: RIZZINI, I. (Org.). A criança no Brasil hoje: desafio para o terceiro milênio. Rio de Janeiro, Ed. Universitária Santa Úrsula, 1993.

PINHEIRO, S. Survivre dans les favelas de São Paulo. Revue Esprit, n.6, juin 1994.

PROGRAMA DE LAS NACIONES UNIDAS PARA EL DESAROLLO (PNUD). Desarollo Humano: Informe, Santiago de Bogota, Tercer Mundo, 1991.

SUDBRACK, U.G. Política Criminal e Interdisciplinaridade, Revista Ibero-Americana de Ciências Penais, Porto Alegre, ano 2, n.2, p.85-93, jan./abr. 2001.

Grupos de Extermínio: aspectos jurídicos e de política criminal. Discursos Sediciosos - Crime, Direito e Sociedade. Rio de Janeiro, Instituto Carioca de Criminologia, ano 1, n.2, p.111-125, 2. sem. 1996.

TAVARES DOS SANTOS, J.V. A violência como dispositivo de excesso de poder. Revista Sociedade \& Estado, Brasília, UNB, v.10, n.2, p.281-289, jul./dez. 1995.

ZAFFARONI, E.R. Em busca das penas perdidas - a perda de legitimidade do sistema penal. Rio de Janeiro: Revan, 1991. 281 p.

ZAMBRANO, M.T. La politique criminelle actuelle au Mexique: quels modéles? 1988. 401 p. Tese (Doutorado) - Université de ParisSud, Paris, 1988.

Umberto Guaspari Sudbrack: Professor do Curso de Especialização em Ciências Criminais da UFRGS. Integrante do Grupo de Pesquisa "Violência e Cidadania" do Programa de Pós-Graduação em Sociologia da UFRGS, Juiz de Direito da $6^{a}$. Câmara Criminal do Tribunal de Justiça do Estado do Rio Grande do Sul (sudbrack@tj.rs.gov.br). 